\title{
A Biodiversidade Brasileira no Âmbito do Acordo TRIPS*
}

\section{Gilberto Mascarenhas}

Engenheiro Agrônomo, MS em Economia Rural, doutorando em

Desenvolvimento e Agricultura pelo CPDA/UFRRJ

\section{RESUMO}

O Acordo sobre Aspectos de Propriedade Intelectual Relacionados ao Comércio (TRIPS), aprovado em 1994, no âmbito da Organização Mundial do Comércio, propugna a harmonização dos sistemas nacionais de propriedade intelectual às suas normas. Entretanto, em função das assimetrias tecnológicas e econômicas existentes entre países periféricos e centrais, das lacunas na própria Lei e da sua convergência apenas parcial com os princípios da Convenção sobre a Diversidade Biológica, a harmonização das políticas nacionais torna-se complexa e, quando aplicada, tem demonstrado efeitos deletérios sobre a economia de muitos países pobres. No Brasil, entre as potenciais conseqüências está a apropriação de recursos genéticos da Amazônia, através de patenteamento por empresas estrangeiras, mas sem transferir tecnologia ou benefícios para o País. Uma saída para critérios de harmonização mais justos poderia ser a aprovação e implementação de uma lei de acesso aos recursos genéticos (já há uma em discussão no Legislativo) que seria a base de negociação das regras do TRIPS.

O autor agradece aos dois pareceristas anônimos da RBI cujas fecundas sugestões contribuíram para o aprofundamento e esclarecimento de algumas idéias e termos utilizados neste artigo. 
Palavras-Chave | Propriedade Intelectual; Inovação; Biodiversidade

Códigos JEL | D23; O31

\section{ABSTRACT}

The TRIPS — Trade Related Aspects of Intellectual Property Rights agreement approved in 1994, in the context of the World Trade Organization, seeks harmonization of national Intellectual Property Rights systems to its norms. However, due to technological and economical asymmetries among poor and rich countries, some gaps in the Law and its lack of convergence with principles of the Convention on Biological Diversity (CBD), makes the harmonization process very complex and, when applied, has caused harmful effects on the economy of many poor countries. In Brazil, one of the most visible consequences of the harmonization could be the appropriation of genetic resources of the Amazon region, and their illegal patenting, by foreign companies, without necessary transfer of technology or benefits to the source country. One more efficient and fair way to manage the harmonization process could be the approbation and implementation of a national law for access to genetic resources, including principles of CBD that could provide an appropriate framework wherein TRIPS rules would be negotiated in a case-by-case basis.

KEYWORDS I Intellectual Property; Innovation; Biodiversity

JEL CODES | D23; O31

\section{Introdução}

No início de século XXI, o domínio da tecnologia e, principalmente, a capacidade de inovação em setores-chave exercem um crescente papel no desenvolvimento e competitividade das nações (Coriat, 2002). Nessa esfera, o conhecimento como bem de mercado assume a cada dia maior importância nas 
estratégias de crescimento de empresas e países. Segundo Arrow, citado por Orsi et al. (2002), o conhecimento quando pode ser assimilado como informação é um bem de mercado que apresenta uma característica importante, sua indivisibilidade, ${ }^{1}$ o que significa que depois de gerado, seu custo de reprodução e disseminação é mínimo se comparado aos investimentos para obtê-lo. Dada a natureza intangível do conhecimento, ele pode ser apropriado por outros agentes (free-riders) caracterizando atitudes oportunistas. Segundo esses autores, os mecanismos de mercado são insuficientes para garantir às empresas o retorno dos seus investimentos em descobertas e inovaçôes caso não sejam amparados em normas direcionadas à proteção da propriedade intelectual. A solução para essa falha do mercado tem sido encontrada por meio de dois incentivos: leis de proteção à propriedade intelectual (patentes, direitos autorais) e subsídios públicos à pesquisa.

No primeiro caso, a perspectiva é principalmente privada (embora seja crescentemente exercitada por instituições públicas) e envolve um monopólio temporário sobre os benefícios potenciais e reais de uma invenção ou descoberta, sob certas condições. No segundo caso, os subsídios governamentais tomam a forma de financiamento a pesquisas, visando o bem-estar da população como um todo, principalmente em áreas ligadas a pesquisas básicas ou naquelas onde o mercado não prioriza investimentos (Coriat et al., 2002).

Segundo Coriat et al. (2002:15), os limites entre o público e o privado na geração de pesquisa básica e aplicada vêm sendo progressivamente eliminados:

“(...) As fronteiras entre conhecimento "público" e "privado" não são estritamente definidas: depende do sistema legal, particularmente da força e do objetivo do sistema de patentes [que o sustenta], e das práticas dos atores com relação à revelação e à troca de informações, definidas por normas informais no contexto das comunidades científicas e profissionais."

\footnotetext{
Para Arrow (apud Orsi et al., 2002), a indivisibilidade do conhecimento está também ligada a economias de escala e à possibilidade de retornos crescentes na atividade econômica. A questão da apropriabilidade do conhecimento, entretanto, é a mais crítica no sentido de garantir o retorno dos investimentos dos detentores de uma invenção, pois o fato de alguém possuir a informação, quando materializada em inovação não impede que outros também venham a usufruir dela. Essa questão não pode ser resolvida através do simples jogo de oferta e demanda, para isso torna-se necessária a criação de aparatos regulatórios que possibilitem a) proteger os investimentos da ação de eventuais freeriders; b) ao gerador do conhecimento, vantagens mercadológicas e competitivas (ao menos por um certo período); c) incentivos para novos investimentos em pesquisa, dado o caráter de risco e elevados montantes de investimentos necessários a determinadas setores, como p. ex., a indústria farmacêutica.
} 
Tais tendências vêm se consolidando principalmente a partir da criação de estruturas "híbridas" de pesquisa entre universidades dos Estados Unidos e grandes empresas, principalmente após o Bayh-Dole Act, de 1980, o qual além de abrir um precedente, tem impulsionado a dispersão desses modelos ao redor do mundo (Coriat et al., 2002; David \& Foray, 2003). ${ }^{2}$

Com base nessas questões, no âmbito da geração e difusão do conhecimento, a principal questão que se coloca é como limitar os custos sociais da inovação, possibilitando, por um lado, cobrir os investimentos do inventor e por outro, distribuir os beneficios da inovação a toda a sociedade? Tal indagação está na origem dos sistemas nacionais de patentes e dos acordos internacionais relativos à proteção da propriedade intelectual negociados no âmbito da Organização Mundial de Comércio (OMC).

Na segunda metade da década de 1980, dois importantes fatores estimularam um recrudescimento do interesse pela proteção dos Direitos de Propriedade Intelectual (IPR) ${ }^{3}$ em bases globais: por um lado, houve crescente reconhecimento por parte de empresas e governos (principalmente em países centrais) sobre a importância dos ativos de conhecimento (knowledge assets) no comércio internacional e por outro, houve pressōes dos Estados Unidos e de outros países economicamente mais ricos, durante a rodada Uruguai do GATT (General Agreement on Tariffs and Trade), para harmonização das normas relativas aos IPR (Aboites \& Cimoli, 2002). A razão alegada por esses países, principais interessados na harmonização, era que as diferenças entre os diversos IPR nacionais criam distorções no mercado internacional e desencorajam investimentos diretos externos, notadamente quando os alvos são os países periféricos. ${ }^{4}$

Tais discussões e negociações no âmbito da OMC desaguaram num acordo assinado em Marrakech, em 1994, intitulado TRIPS (Trade Related Aspects of Intellectual Property Rights). Este acordo definiu um padrão de proteção à propriedade intelectual através de direitos autorais, patentes ou outros instrumentos, no âmbito do comércio internacional (Almeida, 2002).

2 Através do Bayh-Dole Act, foi criado nos EUA o direito de patentear os resultados de pesquisas financiadas por recursos públicos (principalmente instituições acadêmicas) e possibilitar que os resultados possam ser repassados via licenças exclusivas para empresas privadas. Além desses aspectos, há o agravante da cláusula "preference for american industry".

3 Expressão mais conhecida em inglês, como Intelectual Property Rights.

4 Aqui, os conceitos de países periféricos, em desenvolvimento, pobres e do Sul, têm o mesmo significado econômico e geopolítico proposto por Prebisch (1984). A multiplicidade dessas denominações no texto visa refletir os argumentos originais dos autores citados nas referências. 
No contexto do TRIPS, os países membros são obrigados a adequar suas respectivas leis nacionais de propriedade intelectual às novas normas. Embora para países menos desenvolvidos o Acordo tenha previsto um período de "adaptação", não houve preocupação, por parte dos elaboradores das normas, em adequá-las ao nível tecnológico alcançado, ao desenvolvimento empresarial e às demandas nas áreas econômica e de comércio internacional nesses países. Assim, a simples transposição das normas do TRIPS tem causado uma série de controvérsias e conflitos. No caso do Brasil, entre outras distorçōes, pode-se citar o problema do acesso aos ativos da biodiversidade que têm induzido recentes denúncias referentes a biopirataria e a não-observância dos principios da Convenção sobre a Diversidade Biológica (CDB), além de envolver potenciais questôes ligadas à soberania nacional.

O objetivo deste artigo é discutir algumas das implicações do TRIPS no contexto de países periféricos, menos tecnologicamente avançados, mas ricos em biodiversidade, enfatizando a questão do acesso a esses ativos, que constituem uma das principais riquezas desses países e vêm sendo alvo de constantes denúncias relativas à biopirataria. $\mathrm{Na}$ seção a seguir são levantados alguns problemas da implementação desse acordo com relação aos impactos sobre os países periféricos, bem como algumas distorçôes e lacunas existentes na própria lei que podem resultar em obstáculos à sua ampla implementação. Na segunda seção são discutidas algumas implicações do TRIPS sobre ativos da biodiversidade e apontadas algumas perspectivas de intervenção no sentido de o Brasil se adequar a esse acordo de forma menos prejudicial pelo ângulo da negociação de cláusulas que infringem os princípios da CDB.

\section{O Acordo TRIPS e os países ricos em biodiversidade}

\subsection{As assimetrias entre países ricos e pobres}

Um dos principais problemas para a implementação do TRIPS em nível global e, principalmente, para o alcance de seus objetivos em termos de alocação e distribuição dos benefícios da inovação, está nas diferenças marcantes em relação ao grau de desenvolvimento tecnológico ou econômico dos signatários. Uma única regra para todas as nações, principalmente quando o fator relevante 
é a capacidade de absorção e difusão de tecnologias, torna-se crítica e sujeita a controvérsias, cumulando com a não aplicação em grande parte dos casos. $\mathrm{Na}$ medida que a harmonização dos sistemas nacionais aos princípios do TRIPS demanda a existência de um ambiente propício à inovação, a inexistência ou o preenchimento apenas parcial desse requisito na maioria dos países periféricos representa a possibilidade de retrocessos sob o novo sistema. Segundo Aboites e Cimoli (2002), um sistema nacional de inovação deve compor um grupo de instituições que, em conjunto ou individualmente, contribuam para o desenvolvimento e a difusão de novas tecnologias e ofereçam um ambiente propício no qual os governos construam e implementem políticas para influenciar o processo de inovação.

Assim, na ausência das precondições necessárias à inovação, seja no que se refere ao conhecimento tecnológico, infra-estrutura de pesquisa ou mesmo ao capital para investimentos maciços em $\mathrm{P} \& \mathrm{D}$, os países periféricos enfrentam diversas dificuldades na harmonização de sistemas de propriedade intelectual. Entretanto, a adoção de leis que protegem a propriedade intelectual per se, num contexto de harmonização, tende a trazer benefícios globais, como externalidades positivas da inovação (spillover effects), ganhos para a sociedade através das inovações assim estimuladas, e maior difusão de novas tecnologias. Isso seria factível no âmbito de economias cujos mercados fossem competitivos ${ }^{5}$ e onde não houvesse grandes assimetrias econômicas e tecnológicas num contexto de competição internacional.

Para os países periféricos, uma série de problemas torna indesejável a adoção completa do acordo TRIPS, sem que haja adaptações a essas assimetrias. Dentre os principais, está o ônus, para a sociedade, do encarecimento dos produtos em decorrência do longo período de duração das patentes e a elevação do custo de acesso a novas tecnologias, dificultando a sua transferência. Além desses aspectos, a adesão estrita às normas do acordo pode prejudicar a indústria doméstica, dado a seu alcance sobre produtos e processos (Almeida, 2002).

Para Aboites e Cimoli (2002), ao se considerar os problemas de adequação

\footnotetext{
5 Aqui se faz referência a assimetrias na capacidade de investimento em infra-estruturas de pesquisa e no processo de descoberta e inovação por parte de empresas, seja do setor público ou privado; no caso das empresas privadas transnacionais, um mercado competitivo reduziria a possibilidade de existência de lucros anormais de monopólio que reduzem o excedente do consumidor (dead-weight losses) nos países periféricos. Portanto, mesmo no âmbito de uma economia de mercado, haveria a necessidade de que esses mercados fossem contestáveis, no sentido apontado Baumol et al., 1982.
} 
do processo de harmonização do TRIPS em países periféricos, uma primeira premissa a ser evidenciada é que um sistema de inovação não pode desenvolver-se a contento e produzir seus efeitos a menos que o faça no âmago de uma rede social (embeddedness network), onde diversos atores contribuam para um processo dinâmico que além de atingir os objetivos primordiais (tecnológicos), resulta em externalidades positivas para todos os agentes, incluindo empresas, centros de pesquisa, universidades, governo e outras instituiçóes. A experiência da aplicação do Acordo TRIPS em países como no México ou aqueles em processo acelerado de desenvolvimento (NICs) como os tigres asiáticos, demonstrou que, enquanto na Coréia um ambiente propício à inovação com tecnologias, expertise local adequada e infra-estrutura econômica favorável possibilitaram o crescimento da inovação (embora numa determinada direção), o efeito sobre o México foi contrário, devido às características de enclave assumidas pelo seu setor de exportação e as "maquiladoras". Nesse caso, a aplicação do novo regime de IPR no México cristalizou uma maior dependência de tecnologias de países centrais, cuja transferência não possibilitou a sua difusão em termos nacionais.

As vantagens na harmonização dos IPR num contexto como o do TRIPS ocorrem, principalmente, em países mais desenvolvidos econômica e tecnologicamente, onde há grande concentração de atividades de P\&D e esforços visando o desenvolvimento da tecnologia. Esses países possuem características específicas de apoio à inovação, como elevados investimentos em pesquisa (públicos e privados), maior e melhor nível de treinamento da mão-de-obra, elevada articulação em rede das instituições envolvidas na pesquisa, alta concentração no mercado mundial dos líderes da inovação (market share). Em ambientes como esse, o incentivo à proteção dos inovadores é coerente e torna-se a cada dia mais necessário. Já no "limbo" dos países mais pobres, a falta de um tal ambiente e as pressões para harmonizar seus regimes de IPR e abrir seus mercados à globalização (e, portanto, à importação de mercadorias de maior valor agregado), tornam-se fatores críticos que na maioria das vezes podem contribuir para retrocessos tecnológicos, reduzindo assim os potenciais benefícios da harmonização.

Algumas das consequiências e impactos da harmonização dos sistemas de propriedade intelectual no contexto dos países pobres, segundo Aboites e Cimoli (2002), incluem: 
- deterioração dos termos de troca, quando no comércio internacional são transacionadas grandes quantidades de produtos intensivos em conhecimento; muitos países da América Latina, por exemplo, especializaram seu comércio no campo da dotação de fatores naturais e do baixo custo da mão-de-obra;

- a relação entre investimentos diretos externos e a harmonização dos IPRs ainda é ambígua e não ocorre em todos os casos; para cada país há uma situação única a ser considerada onde, a característica do investimento pode demandar diferentes políticas ou incentivos macroeconômicos;

- da mesma forma, a relação entre a endogenização das normas do TRIPS e o crescimento da capacidade tecnológica é ainda muito fraca e, em alguns casos, o inverso;

- o caminho da força, referente à imposição do TRIPS e de algumas práticas de liberalização comercial ${ }^{6}$ gera efeitos negativos no que tange ao desenvolvimento econômico e tecnológico de países periféricos; nesse sentido, as recentes pressões referentes a um "endurecimento" das normas do TRIPS, conhecido como TRIPS-Plus (limitações de cláusulas sui generis, entre outras) por parte dos EUA em alguns acordos bilaterais, apontam para a possibilidade de se aprofundar o fosso entre países centrais e periféricos no que se refere ao desenvolvimento tecnológico.

\subsection{O Acordo TRIPS como um jogo não-cooperativo}

Um exame mais detalhado e em profundidade dos termos da Lei no Acordo TRIPS, suas ambigüidades, lacunas e caráter estratégico foi realizado por Reichman e Lange (2000). Segundo esses autores, o TRIPS, resguardadas as suas vantagens e importância, num contexto de harmonização, representa um jogo de perdeganha, não cooperativo, entre países pobres e ricos. Na mesma linha de Aboites e Cimoli, esses autores colocam em cheque a capacidade de adaptação dos princípios do TRIPS às diversas assimetrias entre países centrais e periféricos, defendendo soluções negociadas caso a caso pelas partes interessadas (o detentor

\footnotetext{
6 A tese de liberalização irrestrita do comércio internacional orquestrada pelos países centrais no âmbito da OMC é contraditória, dado o elevado nível de protecionismo de seus setores agrícolas, por exemplo. Na visão desses países, o livre comércio aqui referido corresponde aos produtos intensivos em capital ou informação que buscam transacionar com os países periféricos, explorando vantagens competitivas.
} 
dos IPR e o país-alvo) via fóruns público-privados. Para eles, o TRIPS deveria representar apenas um grupo de regras (ou princípios) a serem barganhados dentro de um ambiente cooperativo, o que removeria os conflitos da lei numa base negociável, procurando assim maximizar os ganhos de ambas as partes envolvidas na disputa.

Com relação à inadequação da adoção irrestrita do TRIPS em muitas das situações subjacentes aos centrais e periféricos, Reichman e Lange (2000) apresentam dois blocos de potenciais estratégias defensivas por parte desses últimos: barreiras estruturais e expectativas pessimistas.

\subsection{Barreiras estruturais}

No intuito de reduzir os custos sociais decorrentes dos elevados padróes impostos pelo TRIPS, os países mais pobres poderão ser estimulados a construir estratégias no sentido de defender seus objetivos de crescimento quando ameaçados pela nova lei. Dentre as estratégias defensivas possíveis, estão: 1) exploração das ambigüidades da lei; 2) contrabalanceamento de medidas regulatórias; e 3) provisões de salvaguardas.

No primeiro caso, o das ambigüidades possíveis de serem exploradas visando evitar o cumprimento do acordo, uma das fortes limitações para atender aos elevados padrões de exigência é a ainda rudimentar infra-estrutura institucional do sistema internacional de propriedade intelectual e a sua dependência de cooperação por parte de sistemas nacionais. Somente em raros casos a infra-estrutura de resolução de disputas da OMC (panels) estaria apta ou disponível para equacionar essas disputas.

Mesmo no caso de tecnologias tradicionais, subsistem ambigüidades com relação à aplicação dos padrões internacionais, o que permite aos países menos desenvolvidos elaborar estratégias em seu próprio benefício (Reichman \& Lange, 2000). Nessa conjuntura, nada impede os governos desses países negociarem concessões às empresas estrangeiras no tocante aos itens do TRIPS, se isso implicar benefícios para ambas as partes.

Não obstante o caráter fortemente impositivo do processo de harmonização, as premissas a serem cumpridas pelos países signatários, pesadamente calcadas na legislação americana tornam-se inaplicáveis, em diferentes países. 
A estrutura da própria lei, por conter muitas cláusulas amplas (broad legal standards) e ainda não devidamente equacionadas ou implementadas mesmo no âmbito da OMC, também cria oportunidades para diferentes interpretações, favorecendo seu não cumprimento da forma prevista, dada as ambigüidades possíveis.

No caso das compensações ou contrabalanceamentos a medidas regulatórias, a necessidade de atrair investimentos diretos externos, por um lado, e por outro a dependência de tecnologias externas, poderão levar muitos países pobres a sobrevalorizar mecanismos de mercado e a pura competição em detrimento de sua adesão estrita à regulação do TRIPS. Também nesse ambiente de negociação, questôes ligadas à soberania ou que visem atender necessidades de política econômica tornarão mais atrativa a não adesão in totum ao credo da harmonização dos IPR no âmbito do Acordo.

Finalmente, no caso das salvaguardas, a despeito dos mecanismos coercitivos que podem ser implementados pela não adoção ao TRIPS, existem muitos pontos cegos que podem estimular comportamentos estratégicos por parte dos países signatários e, principalmente, o recurso às salvaguardas já previstas em casos onde a aplicação da norma encontra obstáculos econômicos sérios para sua adoção e, nesse caso, a nação pode lançar mão de apelações visando questôes relacionadas a interesses vitais. ${ }^{7}$ Isso é aplicável principalmente no caso dos países mais pobres onde a própria lei, além de conceder prazos de adaptação reconhece a necessidade de ponderar essas situações. Mesmo o recurso a painéis da OMC é sujeito a resultados diferenciados, a depender da filosofia dos membros do conselho.

\subsection{Expectativas pessimistas}

Com relação a uma linha de análise mais pessimista ou cética no tocante ao alcance das expectativas de adesão incontestável da harmonização pelos países em desenvolvimento, Reichman e Lange (2000) lembram que, nesses países, com suas necessidades gritantes de desenvolvimento social e econômico, o principal objetivo passa a ser vencer a defasagem tecnológica e não, necessariamente, a cooperação com esquemas mundiais de proteção a IPR orquestrados

\footnotetext{
7 Para um maior detalhamento desses pontos, ver Reichman \& Lange (2000).
} 
por países que já atingiram um status tecnológico superior ao seu. Os países em desenvolvimento estão mais empenhados em atingir seu próximo estágio, perseguindo o caminho percorrido pelos novos países industrializados (NICs) e, para esse fim, procurarão aproveitar-se de todas as lacunas existentes no TRIPS no sentido de adiantar sua evolução tecnológica. Há, portanto, um conflito básico em conciliar as demandas do TRIPS e as próprias necessidades de desenvolvimento dos países periféricos, podendo levar a retardamentos na aplicação estrita do regime de harmonização ou mesmo, na vigência deste, estimular a busca de lacunas para a implementação de estratégias que os beneficiem.

O que se depreende desse quadro é que, mantidas as regras do acordo TRIPS, o jogo cooperativo só poderá ocorrer em ambiente de negociação, visando otimizar os ganhos para ambos os lados, detentores de direitos e sociedade do país-alvo.

\section{A biodiversidade brasileira e o Acordo TRIPS}

\subsection{TRIPS e CDB: principais fricções}

Segundo Vasconcellos et al. (2003), o Brasil possui a maior biodiversidade vegetal do planeta, concentrando 55 mil espécies de plantas, o equivalente a $22 \%$ do total das espécies já descritas no mundo. Além do grande número de espécies, vastidôes inexploradas como a Amazônia e o potencial de ecossistemas como a Mata Atlântica e os cerrados constituem um patrimônio biológico da maior importância. Aliado a essa riqueza em biodiversidade, o Brasil, juntamente com outros países que integram o ecossistema amazônico, possui um dos maiores repositórios de conhecimentos tradicionais da humanidade (Ferreira et al., 1997). O uso sustentável desse patrimônio representa um trunfo importante para o Brasil no contexto das nações.

A grande questão que afeta países pobres economicamente, mas ricos em biodiversidade como o Brasil, é a baixa capacidade tecnológica e econômica de usar esse recurso de forma sustentável e contribuir assim para o bemestar não só do País como de toda a humanidade. Define-se então uma arena onde, de um lado, estão os países ricos em biodiversidade, mas sem capital e 
tecnologias para usar esse bem de forma sustentável e, de outro, os países ricos economicamente e com o necessário aporte de tecnologias, capital e grande interesse na exploração dos recursos da biodiversidade para fins comerciais.

O jogo que se coloca continua ser o de alocação de recursos e distribuição de benefícios. Os países periféricos, ricos em biodiversidade, além das questôes de soberania, condicionam o acesso a seus recursos à transferência de tecnologias de ponta na área da biotecnologia e à repartição eqüitativa ou justa dos benefícios decorrentes do uso da sua biodiversidade ou dos conhecimentos tradicionais. Com relação às tecnologias ambientais, as preocupações também englobam as assimetrias em relação às capacidades internas para geração, absorção e difusão de tecnologias, dentro das trajetórias tecnológicas já percorridas pelos países desenvolvidos e, ainda, pelas questôes ligadas à proteção da biodiversidade. Os países centrais, através de suas empresas, procuram capitalizar os benefícios das descobertas, não transferem tecnologia e apontam o interesse global, sob a alegação de que a biodiversidade deve ser patrimônio de toda a humanidade. Como resolver essa disputa?

Um dos passos importantes para a resolução desse dilema, não só no Brasil, como em outros países ricos em biodiversidade, foi dado através de um alinhamento do TRIPS com princípios da Convenção sobre a Diversidade Biológica (CDB), propostos durante a Conferência das Nações Unidas sobre Meio Ambiente e Desenvolvimento (Rio-92). A partir desse evento, a preservação e o uso sustentável da biodiversidade deixou de ser uma preocupação exclusiva de ambientalistas e atualmente é ratificada por mais de 150 países.

A adequação das normas do TRIPS aos princípios da CDB tem sido apontada como uma das principais saídas no sentido de se promover a proteção da propriedade intelectual, num ambiente de harmonização de princípios, mas sem representar os problemas ou perdas para os países menos desenvolvidos vislumbradas pela adesão irrestrita ao acordo TRIPS. Esse processo de adequação apresenta, entretanto, alguns conflitos que devem ser resolvidos num ambiente de negociação internacional. Dentre os principais itens de conflito entre o acordo TRIPS e a CDB estão os direitos de patenteamento de microorganismos e o não reconhecimento dos conhecimentos tradicionais. Com relação ao patenteamento de ativos da biodiversidade, o Artigo 27.3 (b) do TRIPS exclui: 
(...) as plantas e os animais, exceto os microorganismos e procedimentos essencialmente biológicos para a produção de plantas e animais, que não sejam procedimentos não-biológicos ou microbiológicos. No entanto, os membros devem assegurar a proteção a todas as variedades vegetais mediante patentes, mediante um sistema eficaz sui generis, ou mediante uma combinação de ambos. As provisões desse subparágrafo devem ser revisadas quatro anos após a entrada em vigor do acordo que estabelece a OMC. (Almeida, 2002:119).

Já a CDB, mostra-se mais coerente com o princípio da defesa dos interesses dos países ricos em biodiversidade, em especial aqueles relativos às restriçóes ao patenteamento de organismos vivos, à proteção dos direitos de propriedade sobre os conhecimentos tradicionais e à repartição dos benefícios resultantes da biodiversidade. De acordo com Almeida (2002), entre as principais diferenças e conflitos entre o Acordo TRIPS e a CDB, no contexto das preocupações por parte dos países ricos em biodiversidade, estão os seguintes:

- a CDB garante o direito soberano sobre os recursos genéticos e a possibilidade de limitar ou proibir o patenteamento de organismos vivos (CDB);

- também permite a proteção dos direitos referentes aos conhecimentos tradicionais e a participação nos resultados econômicos das inovações por parte de comunidades locais;

- o TRIPS permite a propriedade intelectual sobre tecnologias, extensivas às variedades de plantas e microorganismos, embora permita algumas exceções por parte dos países membros (cláusulas sui generis);

- no âmbito do TRIPS as inovações "informais" não são contempladas;

- por esse acordo, o direito de propriedade intelectual não abrange comunidades e sim indivíduos e empresas.

Segundo Hathaway (1996), pelos princípios da CDB o valor da biodiversidade foi classificado como de uso direto e não como opção, o que abre campos para a negociação de benefícios diretos para os países pobres, ou seja, a atribuição de valor econômico à biodiversidade e aos recursos genéticos que ela contém se refere ao valor de uso direto (embora potencial) desses recursos 
naturais particulares na indústria de biotecnologia. No âmbito da CDB, o acesso aos recursos genéticos das nações ricas em biodiversidade e os países ricos em tecnologia e capital, ficou condicionado à permissão de acesso aos primeiros, das tecnologias para uso sustentável desses recursos, bem como a distribuição dos benefícios econômicos daí resultantes.

Entretanto, a questão do acesso às tecnologias mostrou-se problemática em duas vertentes: por um lado há recusa de muitos países ricos em aderir a essa condição do acordo, como é o caso, por exemplo, dos Estados Unidos e, por outro, a defasagem tecnológica e a falta de recursos humanos e financeiros para se dedicar a esses esforços de pesquisa (quando porventura são feitos) na maioria dos países pobres, o que tem dificultado, no plano objetivo, uma adoção mais ampla dos princípios da CDB.

\subsection{A "biogrilagem" de recursos da biodiversidade amazônica}

Nesse contexto de indefinição, um dos setores que mais tem buscado o patenteamento de suas descobertas e, conseqüentemente, insistido na harmonização dos sistemas nacionais de IPR é a indústria farmacêutica. O longo tempo de maturação dos investimentos em pesquisa nessa área e as elevadas demandas em capital têm contribuído nesse sentido. Segundo Ferreira et al. (1997), o custo médio em P\&D de um novo medicamento passou de US\$1,5 a 2,0 milhões no período 1956/62 para US\$ 21 milhões no período entre 1966 e 1972. Esses autores mostram também que já em 1985 esse custo chegava a US\$ 100 milhões, com a perspectiva de ter dobrado esse valor no início dos anos 1990.

Para Orsi et al. (2002), a grande questão subjacente ao equilíbrio entre interesses privados e os da sociedade em geral, na indústria farmacêutica, é "como equilibrar a necessidade de fabricar novas drogas a preços acessíveis à população e ao mesmo tempo manter incentivos na indústria para inventar e desenvolver novos tratamentos?" Na maioria dos casos, principalmente em países periféricos, o custo de medicamentos pode se tornar excessivo e proibitivo devido ao valor das patentes a eles imputado. Em alguns casos de força maior, como durante a explosão da AIDS no Brasil, um problema considerado como de emergência nacional de saúde pública, levou o governo brasileiro a optar por solu- 
ções internas visando a resolução do problema a despeito da camisa de força do TRIPS. ${ }^{8}$ O caminho tomado incluiu, entre outras medidas, o gerenciamento dos preços através da centralização da compra dos medicamentos e a mobilização da indústria local a produzir genéricos, visando tornar o tratamento acessível a um maior número de doentes.

As elevadas despesas com P\&D no desenvolvimento de novas drogas e as incertezas características do processo, segundo Ferreira et al. (1997), além de ter disparado um processo intensivo de concentração e fusão na indústria farmacêutica para fazer frente aos seus custos, tem também levado essa indústria a revalorizar as pesquisas a partir de plantas e extratos naturais (screening), que associadas à biotecnologia e à biologia molecular, apresentam um potencial de redução no tempo de descoberta e inovação. Com relação às plantas medicinais, segundo esses autores, o foco não está na sua utilização pura e simples, mas na identificação de princípios ativos, sendo que, das 250 mil espécies de plantas já identificadas no mundo, apenas $10 \%$ foram investigadas com relação a propriedades terapêuticas. Essas novas tendências incrementaram o interesse da indústria farmacêutica na bioprospecção em todo o mundo.

No vácuo da indefinição mundial com relação a legislações sobre o acesso a recursos da biodiversidade e aos conhecimentos tradicionais a ela associados, mesmo após a CDB, há também elevado nível de desorganização e despreparo dos países ricos em biodiversidade, em implementar leis nacionais. Esse fato tem contribuído para alimentar o interesse, por parte de empresas transnacionais, em aproveitar essas lacunas.

Foi, dentre outras razóes, principalmente devido a esse quadro, que uma série de eventos relativos a biogrilagem ${ }^{9}$ de produtos, marcas e conhecimentos tradicionais vêm ocorrendo no Brasil e outros países da América Latina, deflagrado por empresas estrangeiras. Esse assunto tem sido amplamente noticiado na imprensa brasileira e internacional, envolvendo, em alguns casos, alguma

8 Iniciativa semelhante foi tomada pelo governo dos Estados Unidos frente às ameaças relativas à catástrofe de 11 de setembro de 2001.

9 O termo biogrilagem (biosquatting) foi sugerido em substituição a biopirataria (biopiracy) por Carvalho (2003), chefe da seção de Recursos Genéticos, Biotecnologia e Conhecimentos Tradicionais Associados, da Organização Mundial da Propriedade Intelectual (OMPI), em entrevista à Revista Pesquisa FAPESP. Segundo esse autor, o termo biogrilagem é mais adequado do que biopirataria, ao considerar que nem todos os atos considerados como biopirataria são necessariamente ilegais (para isso demandaria a existência de leis específicas de proteção) e, em segundo lugar, como o termo pirataria é relativo a infração dos direitos do autor, não abrangeria outras áreas da propriedade intelectual, como as marcas e patentes. 
dose de sensacionalismo, mas no geral fundamentado em fatos reais. Por afetarem principalmente produtos da biodiversidade amazônica, jornais da região (O Liberal - Belém-PA e Gazeta do Acre - Rio Branco), revistas nacionais (Veja) e uma ONG do Acre, a Amazonlink (2003) vêm expondo ao público irregularidades no patenteamento de produtos da biodiversidade local por grandes empresas multinacionais. Dentre as principais denúncias, estão (Hathaway, 2002; Amazonlink, 2003):

- Quebra-pedra (Phillanthus niruri Linn) — planta que contém substâncias úteis ao tratamento da hepatite B, além de outros usos.

- Sangue de Drago (Croton lechleri) — seu princípio ativo tem aplicações no tratamento de doenças virais nos pulmóes e contra herpes.

- Ayahuasca ou Santo Daime (Banisteriopsis caapi) — tem funções religiosas entre os povos da Amazônia e seus alcalóides provocam estados alterados de consciência - foi patenteada nos Estados Unidos, através do Plant Patent Act. Nesse caso, uma ONG do Equador, a Coordinadora de Organizaciones Indígenas de la Cuenca Amazônica (COICA) vem realizando uma extensa campanha mundial, mas principalmente dirigida ao governo dos Estados Unidos no sentido de anular essa patente.

- Bactérias - uma ONG dos Estados Unidos, a RAFI, vem denunciando o patenteamento naquele país de diversos microorganismos coletados no Brasil, tais como: a) o microorganismo de solo Ampullariella (isomerase de glicose); b) outro para a produção de streptonigan; c) uma bactéria de solo para produção do complexo de antibióticos CL1565; e um microorganismo para a produção do antitumoral heteroglycans.

- Seringueira (Hevea brasiliensis) — folhas de borracha para a produção de elsinan, como material para películas de embalagem e revestimento.

- Muirapuama - (Ptychopetalum spp.) - planta com propriedades tônicas e afrodisíacas.

Em janeiro de 2003, a ONG Amazonlink (2003), lançou uma campanha contra a biopirataria de produtos da Amazônia, divulgada na Internet e através de diversos meios de comunicação. No documento da campanha intitulado "Limites Éticos Acerca do Registro de Marcas e Patentes de Recursos Biológicos e 
Conhecimentos Tradicionais da Amazônia", esta ONG denunciou a patente de vários produtos amazônicos na Europa e Estados Unidos, inclusive informando a fonte dos dados e os respectivos números de registro. Dentre os produtos patenteados, estão: cupuaçu (Theobroma grandiflora) — marca e processos de obtenção de derivados e ingredientes; andiroba (carapa guianensis) — processos de extração de componentes e utilização na indústria de cosméticos ou de repelentes; copaíba (copahyba spp) — composições cosméticas e alimentares.

Além desses, outros produtos com longa tradição de uso pelos povos da Amazônia já tiveram seus ingredientes, marcas e processos patenteados sem o conhecimento ou anuência prévia do governo brasileiro e cujos benefícios comerciais não foram repassados à sociedade. Um dos acontecimentos recentes que provocaram indignação da sociedade brasileira e internacional foi o caso da biogrilagem do cupuaçu (Theobroma grandiflura), cujo nome e processo de obtenção do óleo para fabricação de chocolate (cupolate) foram patenteados por uma empresa japonesa (Quadro 1).

QUADRO 1

Patentes referentes a cupuaçu e derivados em âmbito internacional

Local de Registro

Reino Unido

Japão

Japão

União Européia

OMPI — mundial

2002

Ano da Publicação

1998

2001

2001

2002

Fonte: Amazonlink.
Título da Patente

Cosmetic composition comprising cupuacu extract

Lipids originating from cupuaçu method for producing the same and use thereof

Lipids originating from cupuaçu Theobroma grandiflorum seed, method for producing the same and its use

Fat originating in cupuassu seed, process for producing the same and use thereof

Fat originating in cupuassu seed, process for producing the same and use thereof 
Obtido de uma árvore nativa da Amazônia, os frutos de cupuaçu têm sido utilizados como alimento há séculos pelas populações indígenas e pelos animais. Segundo a ONG Amazonlink (2003), além dos frutos, os povos da floresta utilizam as sementes desta planta com propósitos medicinais e simbólicos. O uso tradicional do cupuaçu na Amazônia e o crescente interesse em comercialização da sua polpa para fabricação de doces, geléias, bombons, sucos, entre outros preparados, levou à domesticação da planta que passou a ser cultivada. A partir de uma maior produção, a polpa de cupuaçu tornouse um produto comercializado na região, no mercado nacional (fabricação de sucos, doces e sorvetes) e também passou a ser exportada. Segundo Barata (2003), ${ }^{10}$ os dois principais derivados do cupuaçu comercializados são a polpa ( $\mathrm{R} \$ 5,00 / \mathrm{kg}$ na região) e a torta. O cupulate, fabricado por uma empresa norte-americana que obtém um preço até $30 \%$ superior ao do chocolate feito com cacau. Informações no site da ONG Amazonlink (2003), apontam que no primeiro quadrimestre de 2002, apenas o estado do Amazonas exportou para o Japão 50 toneladas de amêndoas ${ }^{11}$ de cupuaçu e a expectativa de exportação para aquele país, em 2003, é de pelo menos 200 toneladas.

Embora noticiado na imprensa que a fruta tenha sido patenteada, esse não é o caso, já que o Acordo TRIPS não permite o patenteamento de plantas. ${ }^{12}$ Com relação ao processo de obtenção do óleo das sementes, para anular a patente, é necessário que o governo brasileiro e as comunidades que se sentem atingidas provem que essa prática é tradicional entre as populações da Amazônia. Sabe-se que houve uma iniciativa da Embrapa em patentear o cupolate mesmo antes da vigência do acordo TRIPS. Segundo Carvalho (2003), essa patente foi solicitada ao Instituto Nacional de Propriedade Industrial (INPI) em 1990 (quando a legislação brasileira ainda não permitia o patenteamento de processos de fabricação de alimentos), com a aprovação da lei brasileira de propriedade industrial, o processo de análise do pedido foi novamente solicitado em 1996, sendo deferido em 1999 e arquivado em 2000. Nesse caso, segundo Carvalho (2003), resta saber se a patente brasileira foi de processo

\footnotetext{
10 Comunicação pessoal em 3/7/2003.

11 Semente seca.

12 Entretanto, a legislação dos EUA é mais flexível nesse sentido e permite esse tipo de patente, uma decisão que fere critérios de patenteamento, como: novidade, contribuição do inventor e aplicação industrial.
} 
idêntico ao japonês, o que permitiria o ganho de causa para o Brasil, por antecedência.

No que se refere ao patenteamento da marca "Cupuaçu”, o procedimento é inteiramente irregular, já que fere o princípio da capacidade distintiva, ou seja, não se pode patentear a marca cupuaçu, nome que é inextricavelmente ligado ao produto e aos seus derivados, não havendo como os concorrentes chamar seus produtos por outro nome. Mesmo no âmbito do TRIPS, o patenteamento da marca cupuaçu fere o Artigo 15.1, que trata da questão da capacidade distintiva (Carvalho, 2003).

Após a questão levantada pelo processo do cupuaçu, várias ONGs da Amazônia, entre elas a Amazonlink, a Associação dos Produtores Alternativos (APA), o Grupo de Trabalho Amazônico e o Instituto Brasileiro de Direito Internacional, da Tecnologia da Informação e Desenvolvimento (CIITED), entraram, em março de 2003, com processo para cancelamento da marca do cupuaçu (marca n. 4.126.269). Ainda em março daquele ano, várias ONGs do exterior passaram a apoiar e fazer campanha contra o registro da marca, em apoio aos brasileiros (Amazonlink, 2003). ${ }^{13}$

Tais problemas apontam para a necessidade de que, no âmbito internacional, haja uma adaptação do Acordo TRIPS aos princípios da CDB e, no contexto nacional, a definição de uma lei que discipline o acesso aos recursos genéticos e aos conhecimentos tradicionais, bem como defina as formas de distribuição dos direitos de propriedade ligados à biodiversidade. No primeiro caso, a Convenção do TRIPS, em âmbito internacional, vem discutindo várias proposições de países em desenvolvimento (ricos em biodiversidade) e de países desenvolvidos que são solidários aos princípios da CDB, no sentido de possibilitar essas adequações (CDBTRIPS, 2003). Com relação ao Brasil, a discussão de uma lei de acesso aos recursos genéticos vem sendo desenvolvida atualmente, conforme descrito a seguir.

\subsection{A legislação brasileira referente ao acesso aos recursos da biodiversidade}

A preocupação com os recursos da biodiversidade brasileira, em termos de legislação iniciou-se com a Constituição de 1988, onde em vez do termo recurso

\footnotetext{
13 Artigos publicados na imprensa em agosto de 2003, apontaram a desistência da empresa japonesa que patenteou a marca e os produtos de cupuaçu de cobrar royalties pela uso do nome por empresas brasileiras.
} 
genético adotou-se patrimônio genético. ${ }^{14}$ Outro desenvolvimento importante, nessa direção, foi o fato de o Brasil, além de sediar a Conferência Rio-92, ter sido um dos signatários da Convenção sobre a Diversidade Biológica, ratificada em 1994 pelo Decreto Legislativo 2/94 e promulgada pelo Decreto 2.519, de março de 1998 (Brasil, 1998).

No Brasil, houve duas iniciativas em normatizar o acesso à biodiversidade com base nos princípios da CDB. A primeira, segundo Hathaway (2002), foi organizada pelo Conselho Indigenista Missionário, da CNBB (CIMI) e pelo Núcleo de Direitos Indígenas (NDI). O objetivo foi, em reação ao projeto de patentes do governo brasileiro, incluir no Estatuto das Sociedades Indígenas (PL 2.057/91) dispositivos para proteger os conhecimentos tradicionais desses povos com relação ao uso de plantas medicinais. A proposta, aprovada em 1994, incluiu direitos sobre bens do patrimônio indígena e direito de propriedade intelectual, inclusive o sigilo e patentes sobre os conhecimentos tradicionais desses povos.

Em 1995, a senadora Marina Silva apresentou um Projeto de Lei (PL 306/ 95) que disciplinava o Acesso aos Recursos Genéticos, envolvendo, dentre outras questôes, as condiçôes de acesso aos recursos da biodiversidade, a distribuição dos benefícios econômicos e tecnológicos, o acesso aos conhecimentos tradicionais e os direitos das comunidades. Entretanto, segundo Capozoli (2003), o governo brasileiro assumiu outra direção, criando o grupo Interministerial de Acesso aos Recursos Genéticos (GIARG). Em 1998, o GIARG encaminhou projeto de lei ao Congresso, repassando à responsabilidade do Executivo a definição da competência dos diversos órgãos ligados à questão. A partir daí, a questão da biodiversidade passou a ser vinculada ao Projeto de Emendas Constitucionais, onde ficou declarado que o patrimônio genético brasileiro passa a ser bem da União. Segundo Capozoli (2003), a falta de um consenso entre Estado, empresas, comunidade científica e ONGs ligadas à questão, impediu até o momento a criação de uma lei definitiva sobre o assunto, que passou a ser regulado por medidas provisórias. A Medida Provisória (MP) 2.186-16, de 23 de agosto de 2001, é um dos documentos que tratam da questão da biodiversidade brasileira. Essa medida regulamenta artigos da Constituição Brasileira e da CDB, e "dispõe sobre o acesso

\footnotetext{
${ }^{14}$ Segundo Vasconcellos (2003), patrimônio genético é "informação de origem genética, contida em amostra do todo ou de parte de espécime animal ou vegetal, fúngico, microbiano ou animal, na forma de moléculas ou substâncias provenientes do metabolismo destes seres vivos e de extratos obtidos destes, vivos ou mortos, encontrados em condições ex situ, desde que coletados in situ no território nacional, na plataforma continental ou na zona esconômica exclusiva." Conhecimento tradicional é definido como "informação ou prática individual ou coletiva de comunidade indígena ou de comunidade local, com valor real ou potencial, associado ao patrimônio genético" (grifo nosso).
} 
ao patrimônio genético, a proteção e o acesso ao conhecimento tradicional associado, a repartição de benefícios e o acesso à tecnologia para a sua conservação e utilização, e dá outras providências" (Brasil, 2001). Em 3/10/2001, o Governo brasileiro, através do Decreto 3.945, definiu a composição do Conselho de Gestão do Patrimônio Genético e estabeleceu "as normas para o seu funcionamento, mediante a regulamentação dos artigos 10, 11, 12, 14, 15, 16, 18 e 19, da MP 2.186, de 23/8/2001 (Brasil, 2001). Este Conselho foi criado com, dentre outras, as seguintes competências":

- coordenar a implementação de políticas referentes à gestão do patrimônio genético;

- estabelecer normas técnicas para a gestão do patrimônio, critérios para autorizaçōes de acesso e remessa, contratos de utilização e repartição dos benefícios, critérios para criação de bases de dados para registro dos conhecimentos tradicionais associados ao patrimônio genético;

- acompanhar processos de acesso e de remessa de material genético bem como do acesso a conhecimentos tradicionais;

- deliberar sobre autorização de acesso e remessa de material genético e conhecimento tradicional associado;

- credenciamento de instituições públicas para autorizar outras instituições nacionais públicas ou privadas, no acesso e remessa de patrimônio genético e conhecimento tradicional associado, quando se trata de envio de amostras para o exterior;

- promover debates e consultas públicas sobre os temas da MP 2.186-16.

Espera-se que, com o andamento das discussóes em torno da MP 2.186-16, relativas aos pontos que têm ensejado conflitos de opinião ou que merecem maior consideração e aprofundamento, o Governo brasileiro possa elaborar uma legislação definitiva que venha regular o acesso aos ativos da biodiversidade no País.

\section{Conclusão}

O Acordo TRIPS, aprovado no âmbito da OMC, por apresentar uma regra única sem ponderar as diferenças tecnológicas, econômicas e de aparato legal entre países pobres e ricos torna conflituosa a sua aplicação indiscriminada. 
Num contexto de harmonização dos sistemas de propriedade intelectual nacionais ao novo regime, os países pobres são os maiores prejudicados, tendo como principais conseqüências a redução da taxa de inovação local, o aumento da dependência tecnológica externa e, em muitos casos, a perda do controle sobre seus ativos da biodiversidade.

A despeito das assimetrias existentes em cada país, seja no âmbito de recursos econômicos, tecnológicos, ou mesmo, na sua dotação em ativos da biodiversidade, numa perspectiva de justiça social e defesa de soberania, tornase claro que, quaisquer leis que disciplinem o acesso a recursos genéticos, especialmente no contexto dos países ricos em biodiversidade, devem ter como base a Convenção sobre a Diversidade Biológica (CDB). A ampla aceitação voluntária da $\mathrm{CDB}$ e sua ratificação por 150 países atestam que os princípios e regras ali definidos são válidos para servir de base a legislações nacionais que disciplinem o uso do patrimônio genético.

No Brasil, a Medida Provisória no 2.186-16, que disciplina o acesso ao patrimônio genético e aos conhecimentos associados, em discussão no âmbito das Câmaras Temáticas do Conselho de Gestão do Patrimônio Genético, por ser baseada na Convenção sobre a Diversidade Biológica, representa um passo importante no sentido do equacionar os problemas relativos à propriedade intelectual na área da proteção da biodiversidade, bem como, em definir um direcionamento estratégico com relação à harmonização através do TRIPS. 


\section{Referências bibliográficas}

Aboites, J.; Cimoli, M., Intellectual Property Rights and National Innovation Systems: Some Lesson From the Mexican Experience, México: UAM-X/ECLAC/UN, 2002.

Almeida, L. T. de, "Comércio e Meio Ambiente nas Negociações Multilaterais”, in Brasil. Comércio e Meio Ambiente: uma Agenda Positiva para o Desenvolvimento Sustentável, Brasília: Ministério do Meio Ambiente, 2002.

Amazonlink. "Limites Éticos Acerca do Registro de Marcas e Patentes de Recursos Biológicos e Conhecimentos Tradicionais da Amazônia”, capturado em 13/7/2003. Disponível em http://www.amazonlink.org/biopirataria/cupuacu.htm

Baumol, W. J.; Panzar, J.; Willig, R., Contestable Markets and the Theory of Industry Structure, Nova York: Harcourt, Brace Jovanovich, 1982.

Brasil. Decreto 2.519, de 16/3/1998. Promulga a Convenção sobre a Diversidade Biológica, assinada no Rio de Janeiro, em 5/6/1992. Diário Oficial. Brasília, 1998.

Brasil. Decreto 3.945, de 3/10/2001. Define a composição do Conselho de Gestão do Patrimônio Genético e estabelece normas para seu funcionamento. Diário Oficial. Brasília, 2001.

Brasil. Medida Provisória, n. 2.186-16, de 23/8/2001. Regulamenta artigos da Constituição e da Convenção sobre a Diversidade Biológica e dispõe sobre o acesso a patrimônio genético [entre outras coisas]. Diário Oficial. Brasília, 2001.

Capozoli, U., "Medidas Provisórias são Fonte de Polêmica", in Biodiversidade: valor económico e social, capturado em 11/7/2003. Disponível em http://www.comciencia.br/reportagens/ biodiversidade/bio10.htm

Carvalho, N., "Em Defesa da Biodiversidade", in Revista Fapesp, n.84, fev., 2003.

CDB-TRIPS Discussion picking up speed at the WTO. Proposals of Swiss, India, Brazil and other countries related to biodiversity and traditional knowledge. Received by e-mail from [coutinho@inpi.gov.br] in 3/7/2003, referring to WTO meeting on 4, 5 and 6 of June.

Coriat, B. The New Global Intellectual Property Rights Regime and Its Imperial Dimension: Implications for North-South Relations, Paris: Université Paris 13, 2002.

; Orsi, F.; Weinstein, O., Science-based Innovation Regimes and Institutional Arrangements: Fom Science-based "1" to Science-based “2” Regimes, Paris: Université Paris 13, 2002.

David, P. A.; Foray, D., "Economic Fundamentals of the Knowledge Society”, in Policy Futures in Education - An e-Journal, 1(1): Special Issue: Education and the Knowledge Economy, Jan., 2003. 
Ferreira, S. H.; Barata, L. E. S.; Salles-Filho, S. L. M.; Queiroz, S. R. R. de, Medicamentos a Partir de Plantas Medicinais no Brasil, Campinas: Academia Brasileira de Ciências/Unicamp, 1997.

Hathaway, D., "Lei de acesso aos recursos genéticos: soberania e justiça social na pauta das políticas nacionais", in Fórum Brasileiro de ONGs e Movimentos Sociais para o Meio Ambiente. Brasília: Senado Federal, 2002 (no prelo). Biodiversidade, Biotecnologia e Patentes no Brasil, São Paulo: AS-PTA, 1996.

Orsi, F; Coriat, B.; Weinstein, O., From Marrakech to Doha: Some Reflections on the Foundation of Patent Regimes in the Pharmaceutical Industry, Paris: Université Paris Nord, 2002.

Prebisch, R., "Five Stages in my Thinking on Development", in Meier, G. M.; Seers, D., in Pioneers in Development, Oxford: Oxford University Press, 1984.

Reichman, J. H.; Lange, D., "Bargaining Around the TRIPS Agreement: the Case for Ongoing Public-Private Initiatives to Facilitate Worldwide Intellectual Property Transactions", in Duke Journal of Comparative \& International Law, v.9 (11), p.11-68, 2000.

Vasconcellos, A. G., Propriedade Intelectual dos Conhecimentos Associados à Biodiversidade, com Ênfase nos Derivados de Plantas Medicinais: Desafios para Inovação Biotecnológica no Brasil, Rio de Janeiro: UFRJ, Tese de Doutorado em Biotecnologia Vegetal, 198p., 2003.

; Esquibel, M. A.; Lage, C. L. S., "Proteção Patentária de Fitoterápicos no Brasil: um Estudo Sobre os Depósitos de Patentes ao Longo da Década de 90”, in Revista Brasileira de Plantas Medicinais (no prelo), 2003. 